any inflammation. But the eye is not normal; it is in my opinion suffering from chronic sympathetic ophthalmitis, and it is possible that there might be a flare up with serious consequances. The excised eye was examined by Mr. Treacher Collins, and he reported that it showed the typical Fuchs choroiditis, and that it was in his opinion a dangerous eye. It is possible that had I retained the eye it would have made a complete recovery, and that the girl would have two useful eyes instead of one. A case almost exactly the same seen two years later at Leamington, was treated with N.A.B. The injured eye was not removed, and both made a complete recovery as far as I know. This case was last examined in June, 1942. A little fine pellucid "K.P." was still present, but the eye was otherwise normal.

\title{
A CHOROIDAL MELANOMA TREATED BY SURGICAL DIATHERMY
}

BY

\author{
- L. H. Savin and G. C. Pritchard \\ LONDON,
}

THE following case raises interesting questions for discussion :-

On December 3, 1941, L.U,, an R.A.F. corporal, aged 37 years, attended medical outpatients at King's College Hospital, complaining of severe headaches, which frequently incapacitated him. He was seen by Dr. Brigden, who found no general or local cause for the pain. His Wassermann reaction was negative. He was referred to the eye department. Here he was carefully refracted and pronounced emmetropic. Vision was $6 / 5$ in each eye. Fields were normal and there were no abnormal scotomata. His eyes were normal except for a small choroidal melanoma of the left eye (Fig. 1). The melanoma extended above to a branch of the central vein; its lower pole just touched a branch of the artery. Provisionally the tumour was diagnosed " choroidal mole "; but the patient was kept under observation. Three weeks later the lower pole of the tumour was found to extend to the other side of this branch of the artery-the growth was extending slightly, and appeared to be one of the rare cases of a malignant melanoma developing from a benign pre-existing melanoma (Grinker, 1940).

Choice of treatment was difficult. Our first impulse to enucleate the eye was restrained by the unexplained headaches, which we thought might indicate secondaries, and the good vision in the eye $(6 / 5)$. As the growth was small we decided to destroy it by surgical diathermy. The position of the growth was carefully localised ophthalmoscopically. 
On January 1,1942 , an operation was performed under retrobulbar and subconjunctival novocaine anaesthesia. The inferior rectus was infiltrated with novocaine and for conyenience the faciai nerve was blocked.

- Lt was found easy to expose the sclera over the affected area without any resection of the inferior rectus. The ordinary $2.5 \mathrm{~mm}$.

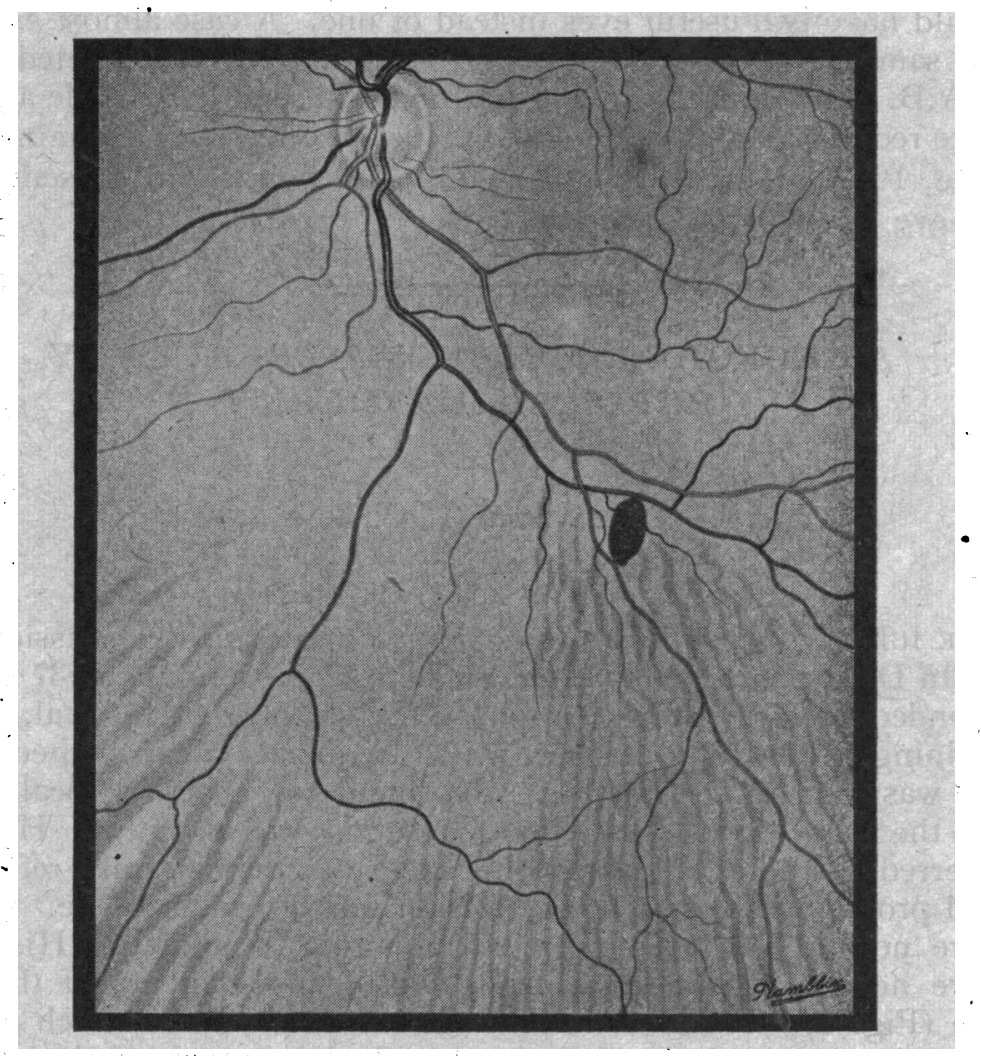

FIG. 1.

The melanoma when first seen.

flat electrode deseribed by Weve (1940) was employed on the Keeler diathermy unit using a 120 ma. current for three seconds. The first application was about 1 disc-diameter too far forward; but the second application was right on the melanoma.

Ophthalmoscopy showed a white circular area of burn exactly over the tumour. The retinal vessels were in a state of spasm, which could be seen to pass slowly along them during the period of observation. 
By January 30,1942, the eye had settled down. There was no loss of central vision; but a peripheral sector defect could be demonstrated on the perimeter $(2 / 330$, white object $)$. The formerly dead white diathermy marks in the fundus were now becoming surrounded by pigment (Fig. 2).

On April 14, 1942, this pigmentation had considerably increased in both areas, but in the tumour area there appeared, in the white

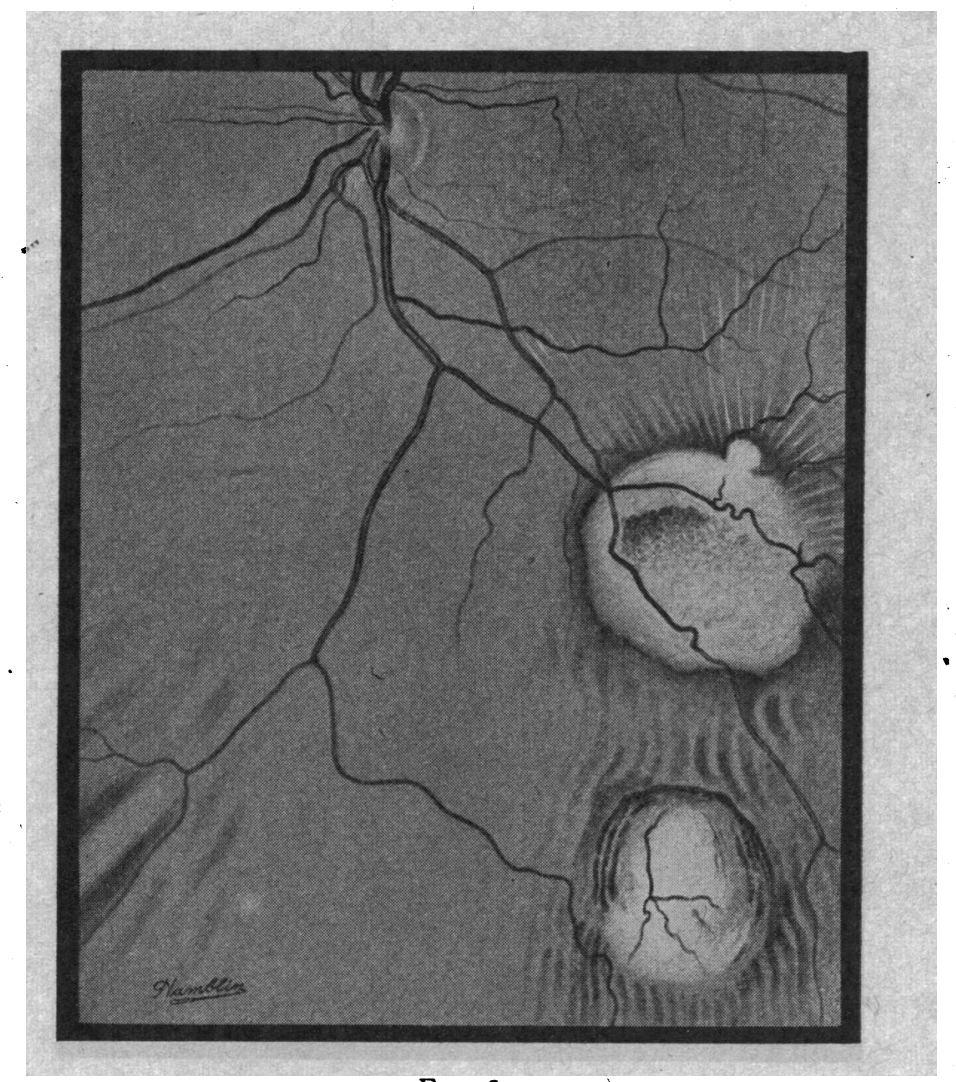

FIG. 2.

Twenty-eight days after operation.

ring, a pigment patch which was less black and was the shape and size of the original tumour. This appearance raised the question of recurrence, but Mr. A. D. Griffith thought it was due to the pigment of the dead tumour becoming apparent as the overlying coagulated retina became transparent. There were a few haemorrhages from damaged retinal vessels. The retina in the area around the patches was raised into folds as if by contraction of the scars (Fig. 3). 
On July 14, 1942, pigmentation was more increased and some retinal haemorrhages were still visible (Fig, 4). Since then there has been little change in the fundus appearances. The patient is in good health except for the headaches, which still cause him trouble periodically. The haemorrhages are absorbing.

1. The patient cannot be considered out of danger while the unexplained headaches persist, in spite of a history of similar, though apparently worse, attacks in his father.

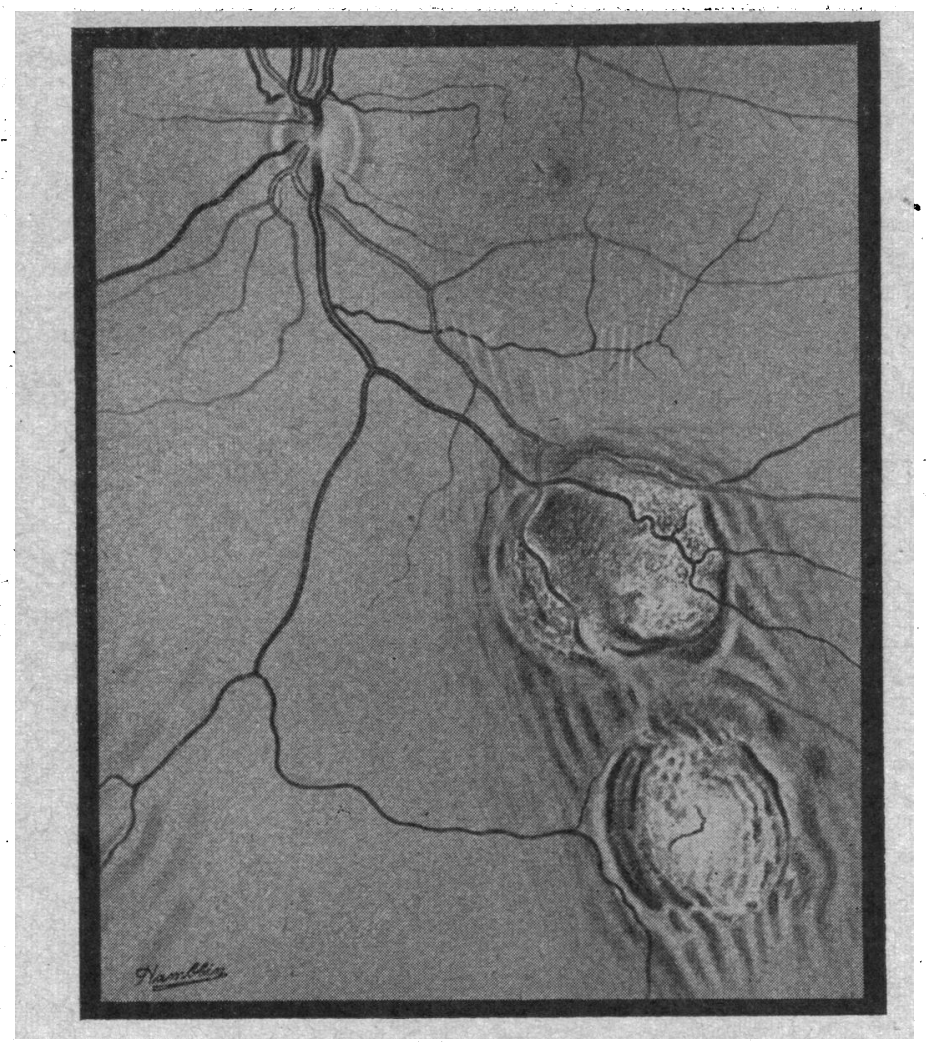

Fig. 3.

Appearance on April 14, 1942.

2. The diathermy seems to have caused adequate local destruction of the growth and to be a useful method in selected cases of choroidal tumour. (See also cases reported by Weve, 1939).

3 . In this case it is hard to suppose that much additional safety would have been attained by an enucleation, especially in view of the high recurrence rate reported after enucleation for melanoma (Pahwa, 1941). 


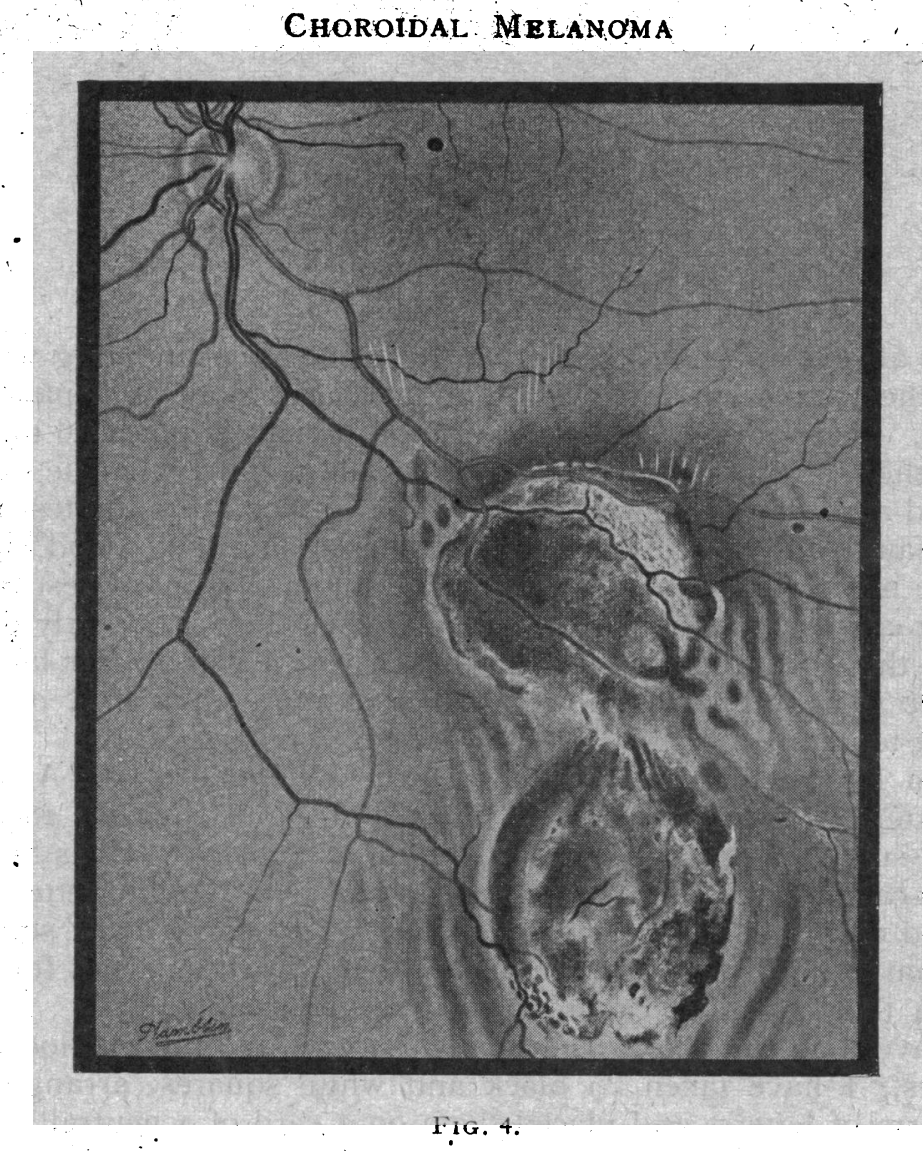

Appearance on July 14, 1942.

4. The "sighting shot" with the diathermy in this case was accidentally made through faulty localisation. A scar for comparison purposes on a normal area of retina proved, however, to be extremely valuable. We shall make such a scar deliberately in future "cases, if by some fluke we strike the tumour at the first application.

We wish to thank Messrs. A. D. Griffith, F. Ridley, W. T.C. Lumley, and T. H. Whittington, for much helpful advice and assistance.

\section{REFERENCES}

GRINKER, R. R. (1940).-Modern Trends in Ophthalmology. Butterworth and Co., p. 488 .

PAHWA, T. R. (1941).-Brit. Jl. Ophthal., Vol. XXV, pp. 241-286.

WEVE, H. J. M. (1939).-Trans. Ophthal. Soc. U.K., Vol. LIX, Part 1, pp. 61-64.

(1940).-Modern Trends in Ophthalmology. Butterworth and Co., pp. 553-572. 